Research Article

\title{
Systemic Risk Contagion in Reconstructed Financial Credit Network within Banking and Firm Sectors on DebtRank Based Model
}

\author{
Yuetang (Peter) Bian, ${ }^{1}$ Yu Wang, ${ }^{1}$ and Lu Xu ${ }^{2}{ }^{2}$ \\ ${ }^{1}$ School of Business, Nanjing Normal University, Nanjing, China \\ ${ }^{2}$ Office of Academic Affairs, Nanjing Institute of Railway Technology, Nanjing, China \\ Correspondence should be addressed to Lu Xu; nj_xulu@163.com
}

Received 19 August 2020; Revised 20 November 2020; Accepted 27 November 2020; Published 10 December 2020

Academic Editor: Lin-Yun He

Copyright (c) 2020 Yuetang (Peter) Bian et al. This is an open access article distributed under the Creative Commons Attribution License, which permits unrestricted use, distribution, and reproduction in any medium, provided the original work is properly cited.

\begin{abstract}
This paper is dedicated to building a multilayer financial network within banking sectors and firm sectors (nonbanking) on the balance sheet of two types of agents and to assessing systemic risk contagion in the reconstructed network. Two propagation channels due to interbank credit and counterparty risk via banks' loans to firms are comprehensively taken into account in systemic risk contagion assessment, which is based on the DebtRank model by analyzing the relative loss of each bank's equity and the vulnerability of the network. The computational simulation on how systemic risk contagious process evolves has been conducted, where the possible influential factors of network structure, agent's initial risk status, external shock ratio, liquidity flow rate, and different layers of the network are considered. The findings show that the reconstructed network is absolutely vulnerable under the assumed market circumstance without any bailouts and the risk contagion process shows nonlinear behavior. Specifically, when the average degree of the network and the external shock ratio increases, the risk contagion speed becomes relatively high and the resulting negative effects on the network are more intense. Besides, risks originating from the failed firms in bank-firm layer should place more negative effect on the financial system than that only happening in interbank market. Different liquidity rates in financial market could lead to obvious discrepancy of the risk contagion speed and the extent of asset loss. Additionally, the two layers of the network have diverse influences on risk contagious process resulting in totally different banks' status in each layer.
\end{abstract}

\section{Introduction}

The financial crisis of 2007-2008, originally sparked by the collapse of relatively small investment banks, has caused magnified losses for numerous financial and nonfinancial institutions eventually and ultimately led to a worldwide economic slump. The Bank for International Settlements (BIS) and the International Monetary Fund (IMF) believed that financial systemic risk would lead to functional disorder of the financial system and actually place serious impact on real economy, due to the interrelationships between them [1]. Therefore, the emergence of systemic risk in financial networks has been receiving increasing attention in the literature $[2,3]$ and regulators (Yellen [4]). Generally, systemic risk in financial markets can be seen as a specific risk that a significant fraction of the financial system can no longer perform its function as a credit provider and collapses. Briefly speaking, systemic risk is the notion of contagion or impact that starts from the failure of a financial institution and propagates through the financial system, potentially to the real economy $[5,6]$. Network places paramount effect on systemic risk and financial stability because shocks can be amplified and transmitted across various channels both directly and indirectly, including credit lending [7-10], common funding [11, 12], balance sheet interlock [13, 14]), exposures to common assets [3, 15-17], derivative exposures [18], and deleveraging across financial institutions $[19,20]$. In view of this, 
network-based systemic risk is extremely harmful and can be potentially applied to evaluate the financial risk, which has already been testified by the academic circles and regulation authorities.

Until now, lots of researches have been done on whether the network structure can amplify or mitigate risk within the financial systems, at both regulatory level [21] and institution level $[19,22]$. These achievements have accelerated the research on systemic risk and financial networks for different purposes, especially on the measurement of systemic risk from the network perspective [14, 18, 23-25]. However, other than the most works on systemic risk in single layer financial network, some works have already extended the notion of systemic risk to be explored in multilayer networks, which is much more complicated than the simple accumulation of the risks in homogeneous single layer network [26]. Concerning the multilayer network-based financial risk analysis, recent literatures have appeared and spurred the future exploration [26-33]. León et al. [29] and Bargigli et al. [30] analyzed the interactions of financial institutions on different markets in Colombia and Italy, respectively. Bluhm and Krahnen [28] designed an agent model of multilayer interbank network with the channels of common asset exposure, direct lending exposures, and fire sales. Montagna and Kok [27] studied the individual contagion layer to systemic risk through the multilayer networks with three layers: long-term direct lending exposures, shortterm direct lending exposures, and common asset exposures. Poledna et al. [26] showed that the risk was greatly underestimated only in a single layer network and quantified the contribution of the four-tier network of Mexican banking system on systemic risk. Peralta and Crisóstomo [31] divided the bank network structure into two layers based on the type of mortgage-free transaction and showed that the speed of risk transmission under the multilayer network structure was more rapid. Korniyenko et al. [32] constructed a multilayer network based on the division of different financial instruments and analyzed the transmission of risks in global financial networks. Li et al. [33] constructed a multiplex network model of banks with arbitrary structural characteristics by long-term and shortterm interbank lending.

In real markets, especially in some emerging markets, banks are the main creditors to the real economy in financial system, but part of the large firms (nonbanking) also has these similar financial functions to the banks, which means that financial crisis could also originate from the real economy and spread to the financial system even the whole economy in back and forth way. Therefore, the topology of financial networks can be adopted to identify and quantify systemic collapse systematically, and the networks should not only comprise financial institutions, but also include certain industrial firms [34-36]. To our knowledge, only a few works empirically and theoretically study the interrelationship between the financial economy and the real economy [37-40]. Moreover, De Masi et al. [41] and Miranda and Tabak [42] studied credit networks in Italy and Brazil empirically, while Lux [43] developed a theoretical model of bipartite credit networks. Marotta et al. [40] investigated the evolution of the network structure in Japan and then identified the communities in the composed financial network between banks and firms. Except for the concentration on the structure of bank-firm networks, systemic risk assessment in them has also been put forward. Miranda and Tabak [42] and Aoyama [39] firstly attempted to study systemic risk in credit networks of Japan and Brazil empirically. In these works, several measures for systemic risk have been proposed that are mostly based on the traditional statistics of losses, accompanied by a potential distress during the periods of risk contagion [44-46]. However, none of these measures take cascading defaults into account. As a complement solution, network-based theory and measures, such as network centrality approach and its derivations, have been great contributions to understand this issue.

Therefore, considering the interrelationship between the financial department and the real economy sector, financial risk not only happens when the institutions directly are shocked, but also has adverse impact on the deterioration of credit quality [47] in this complicated financial system. We extend the existing literature by reconstructing and analyzing a synthetic financial network that not only includes interbank liabilities but also covers the lending relationship from banks to firms. The theoretical reconstruction of financial network within banking and firm sectors allows identifying the assessment systemic risk contagion by employing DebtRank algorithm as proposed in Battiston et al. [14] and Bardoscia et al. [48], whose derivation has been approved useful in several works $[26,49]$.

This paper is organized as follows: the two-layer financial credit network model between banks and firms is reconstructed theoretically in Section 2, and the systemic risk contagion mechanism in the reconstructed financial network is presented in Section 3. Section 4 builds a systemic risk contagion model on DebtRank model. In Section 5, simulation analysis is conducted. Section 6 draws the conclusions.

\section{Reconstruction of Financial Network within Banking and Firm Sectors}

In order to capture the systemic risk contagion effects in financial system precisely, joint exposures via different channels to the same set of correlated agents should be included. With regard to this, a consistent and extremely close to realistic network structure for each type of agents within different but combined channels should be designed, especially for the financial bipartite network of banks and firms. Some basic and reasonable stylized realities can be inferred from the analysis of comprehensive empirical studies on Italian data [41], Japanese data [37-39], Brazil data [42], and Austrian data [50], which have been simply described and explored in some related articles [43, 50].

In most of the empirically analyzed articles on bipartite networks, the distribution of degrees is always wider for banks than for the correlated firms $[38,50]$, and the number of links of the networks also depends on the size of each agent in the network system $[37,41]$. Based on the above 
literatures, we aim to reconstruct a multilayer financial credit network within banking and firm sector theoretically by adopting the hypothesis and the algorithm proposed in the directional articles of Montagna and Lux [51], De Masi and Gallegati [38], and Lux [43]. A two-layer financial directed network is to be established as $G=(V, E)$ in this article, where $V$ and $E$ represent the nodes and links, respectively, consisting of interbank credit layer and bank-firm credit layer. Basically, the schematic diagram of the reconstructed network can be depicted in Figure 1.

Above all, we set a fix number of banks and firms in our reconstructed network system, and it is certain that number of the firms in real economy exceeds that of banks by two or more orders of magnitude. Meanwhile, we assume that the balance sheet size of the banks and firms both follows Pareto distribution which is well-known insights in reality $[43,51]$. Therefore, interbank credit layer network and bank-firm credit layer network are reconstructed specifically in the following sectors. For all, we denote the number of banks and firms in the network by $N_{b}$ and $N_{f}$, respectively.

2.1. Interbank Credit Network. In interbank network, the edges are directed and weighted, and the direction of a link from node $i$ to node $j$ means the total amount of money that bank $i$ lends to bank $j$. Following Montagna and Lux [51], we adopt that simplified scheme of the agents' balance sheet. The assets side $A_{i}$ of each bank can be partitioned into two parts: interbank loans $l_{i}$ and external assets $x_{i}$ (loans to firms), so that the total assets $A_{i}$ can be given as $A_{i}=l_{i}+x_{i}$. In the same way, the liabilities $L_{i}$ of each bank can be divided into three parts: interbank borrowing $b_{i}$, deposit $d_{i}$, and equity $e_{i}$, so the liabilities side can be obtained as $L_{i}=b_{i}+d_{i}+e_{i}$.

Therefore, the links between the banks can be generated by the probability generating functions $P\left(A_{i}, A_{j}\right)$ according to the relative sizes $A_{i}$ and $A_{j}$ of balance sheets [43], which is in accordance with the fact that relatively small and medium sized financial entities usually lend money to much bigger banks so as to reallocate liquidity to the market more efficiently $[10,11,52]$. Therefore, the probability of the interbank credit link between each node $i$ and node $j$ can be drawn as $p_{i j}=P\left(A_{i}, A_{j}\right)=d\left(A_{i} / A_{\max }\right)^{\alpha}\left(A_{j} / A_{\max }\right)^{\beta}$, where $\alpha, \beta, d$ are parameters and $A_{\max }$ is the balance sheet size of the largest bank. With the probability generation function, $N_{b} \times N_{b}$ probability matrix $P \in M_{N_{b} \times N_{b}}$ can be obtained accordingly. Then, each entry of the interbank network adjacency matrix $A$ can be drawn with the probabilities $p_{i j}$ and $1-p_{i j}$ so as to make sure that the interbank credit link can be created. Meanwhile, the selected probability generation function, which can be used to capture the right-skew of the degree distribution and the disassortative feature of link formation, has been explored and testified in recent researches [10, 53].

Naturally, it is assumed that financial entities should always have more intense links to the banks with high balance sheet size; the volume of credit $l_{i j}$ between each bank $i$ and $j$ can be calculated as $l_{i j}=\left(l_{i} p_{i j} A_{j} / \sum_{k \in \Omega_{i}} p_{i k} A_{k}\right)$, where $\Omega_{i}$ denotes the set of nodes with $a_{i j}=1$. Thus, the interbank credit network can be constructed theoretically.

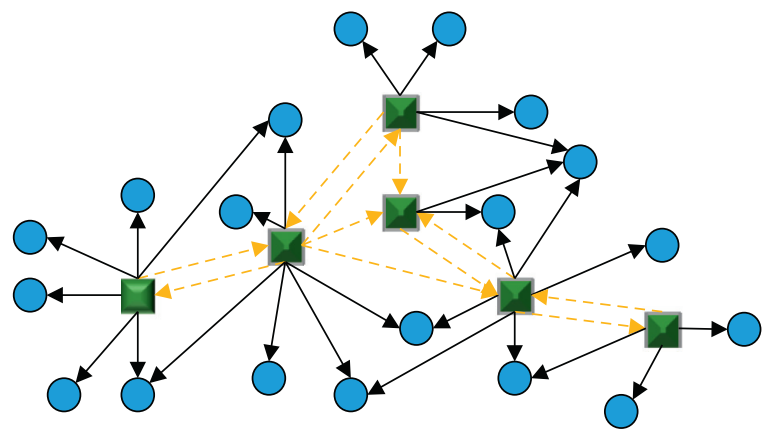

FIgURE 1: Simplified framework of two-layer bank-firm credit network. The green squares and the blue circles represent banks and firms, respectively. Meanwhile, connections of the black dashed lines and the yellow dotted lines represent the interbank credit and bank-firm credit, while the arrows mean the credit direction.

2.2. Bank-Firm Credit Network. On bank-firm credit network, let the average number of links of firms be $\lambda_{f}$, so the average number of links for each bank can be $\lambda_{b}=\lambda_{f}\left(N_{f} / N_{b}\right)$, but does not follow uniformly and shows the means of linking probabilities across the banks and firms varying by their balance sheet sizes. Therefore, the procedure of reconstructing the bank-firm financial network should be conducted on banks and firms separately.

For banks, each one's total assets $A_{i}, i=1,2, \ldots, N_{b}$, can be distributed as $f(A) \sim\left(\left(\alpha L^{\alpha} A_{i}^{-(\alpha+1)}\right) /\left(1-(L / H)^{\alpha}\right)\right)$ that the balance sheet sizes of banks could be got from a truncated Pareto distribution randomly, where $L$ and $H$ are the lower and the upper limit, respectively, and $\alpha$ is the Pareto index. Besides, we also assume that the degree of each bank (the links number of each bank) is distributed proportionally to its balance sheets sizes, so that bank $i, i \in\left(1, N_{b}\right)$ has an expected degree $\lambda_{i}=\overline{\lambda_{b}} A_{i}$. Therefore, the average expected degree across the banking sectors can be calculated as $\int_{L}^{H} \overline{\lambda_{b}} A_{i} f\left(A_{i}\right) \mathrm{d} A_{i}=\lambda_{b}$, where the constant $\overline{\lambda_{b}}$ is simply obtained as $\lambda_{b}=\lambda_{b} / \bar{A}_{i}$, representing the average degree $\lambda_{b}$ divided by the mean balance sheet size $\overline{A_{i}}$ within the financial system.

For firms, the distribution of loan sizes and degrees can also be consistent with those obtained for banks and the typical facts represented above. Therefore, the mean size of firms' loan can be obtained as $\overline{f_{i}}=\theta \overline{A_{i}}\left(N_{b} / N_{f}\right)$, where $\theta$ is the proportion of the assets as loans to firms in bank's balance sheets. Supposing that the distribution of firm size also follows a Pareto distribution with the same parameter $\alpha$ as for banks, the truncated Pareto distribution for firms can be therefore obtained by adopting the minimum threshold $l$ and maximum threshold $h$ in the same way that are $l=$ $\theta L\left(N_{b} / N_{f}\right)$ and $h=\theta H\left(N_{b} / N_{f}\right)$. For the number of firms being absolutely larger than that of banks, it is guaranteed that the loans by firms should appear on the left side of the size distribution of banks, with the distribution of aggregate loans in banks' balance sheet. Thus, the realization for the ensemble of firms can be obtained just like the way for banks, and the number of links of each firm $j=1,2, \ldots, N_{f}$ can be drawn with the above parameters $\lambda_{j}=\overline{\lambda_{f}} B_{i}$, so that the 
average number of that can be obtained as $\overline{\lambda_{f}}=\lambda_{f} / \overline{B_{i}}$, where $\lambda_{f}$ and $\overline{B_{i}}$ are the average degree and the average loan size across firms.

Overall, in addition to the total loans from the banks to firms, the obtained numbers of the degrees for all banks and firms should be roughly accordingly set up to the initial expectation. In order to make it more consistent with the reality, especially for the difference of both numbers exactly, the approach of static model for network reconstruction is applied [54], which is operated by taking the minimum of the aggregate links and adding connections one after another. From this, the steps of network reconstruction can be conducted as follows: first, each bank or firm will be assigned a weight according to the realization of its degree. Then, we pick one node from the weighted ensemble of banks and firms, respectively, and create a link between them. Hereafter, the previous used link from the distribution of degrees of banks and firms will be excluded from the set of possible links each time, and the same operation of building the connection will be preceded until the available links from either banks' or firms' side run out. At last, the total loan amount of each bank is allocated to its borrowers (firms) proportionally to their loan sizes by Pareto distribution of firms. If so, this could guarantee the possible increase of degrees with loan size within firms to large extent, avoiding the potential errors that the exact numbers would not be absolutely the sum pertinent loan position of banks that have been generated independently.

\section{Systemic Risk Contagion Mechanisms in Reconstructed Network}

On the existing literatures, we go through the whole banking and firm sectors and analyze how default or distress is evolving in the two-layer financial credit network. Normally, it is assumed that external shock on the financial network system should damage the equity of the shocked firm(s) or bank(s). Moreover, it is expected that the shocked firms or banks should linearly transfer the loss of equity to the creditor banks. In the network, the risk exposure is supposed to be short-term loan, and the credit from banks to firms is assumed to be a highly liquid asset for creditors. Normally, if banks are faced with liquidity risk, credit risk, and the parallel influences, they could adopt several solutions to avoid these possible risks. Meanwhile, if a bank suffered from liquidity crisis, regardless of the solutions to be taken by the bank, negative effect would be placed on for different reasons, which may be resulting from high interbank interest's rate, asset devaluation for fire sale, etc. In general, the diagram of systemic risk contagion mechanism in financial credit network within banks and firms can be portrayed as shown in Figure 2.

According to the diagram of the systemic risk contagion mechanism, the institutions face losses in all classes of assets, both interbank market and the bank-firm financial market, and the framework of dynamics of the relative loss in equity for each institution as well as the whole system is concerned. Systemic risk contagious process and how it places impact on the stability of the financial network system can be depicted as the following two rounds.

(1) The first round of shock is on the external part of the assets. Initially, it is supposed that one or more nodes in the financial network that may be firms or (and) banks suffered from external shock and we can let $m$ be the shock ratio, representing the loss extent of the shocked agents' external assets.

For banking system, after the first round of shock, shocked banks may lose part of the assets amount to $m V^{\mathrm{OI}}(0)$, where $m$ represents the extent of the damage caused by the first round shock. However, the liabilities will be unchanged for the book value regardless of how the shocks are going. In the same way, the equity of the shocked firms should be also damaged and suffer from the loss of $E_{f}(1)=(1-m) E_{f}(0)$.

Due to the external shock, even if the shocked bank(s) should not default, the panic of default or the probability of default still spreads within the network system, placing especially negative impact on the creditor banks or other correlated agents. Meanwhile, creditor banks also face the dilemma of repayment for their own debts and have to sell assets.

However, it is difficult for banks to sell assets without realizing losses under market liquidity deteriorate; that is, their assets should be traded at a certain discount rate. Therefore, in this paper, we let $q$ be the asset flow rate reflecting the market liquidity, so that the banks would sell the assets with the book value $\left(\left(m\left[V^{\mathrm{OI}}(0)+a_{f t}(0)\right]+\sum_{E_{b}(t-1) \leq 0} a_{b i}(t)\right) / q\right)$ to make up for the funding shortage.

(2) The second round of shock is on the assets within the bank-firm credit network. In this round, shocks on the asset side of the balance sheet of the firm(s) or bank(s) propagate along the network; even such shocks are not large enough to trigger the default of these agents. Banks would make the evaluation of the shocked counterparties' ability of paying the loans. This is motivated by the fact that as one agent's equity decreases, so does its distance to default [55], and it will be less likely to repay its obligations in case of future distress. Therefore, banks should have incentives to draw back credit from the correlated institutions or make liquidity hoarding to them in case of the default. If so, banks can make self-rescue when their assets are lower than a certain value, which could be the benchmark of the bank's compulsory leverage. Meanwhile, it is also presumed that the banks should make the decision of drawing back the credit from the firms randomly, whoever has credit-lending relationship with them.

As far as banks are concerned, drawing back credit may avoid potential loss of assets, but it could place negative impact on the counterparty agents. It is assumed that being drawn back credit firms or banks should go bankrupt potentially and their liquidation 


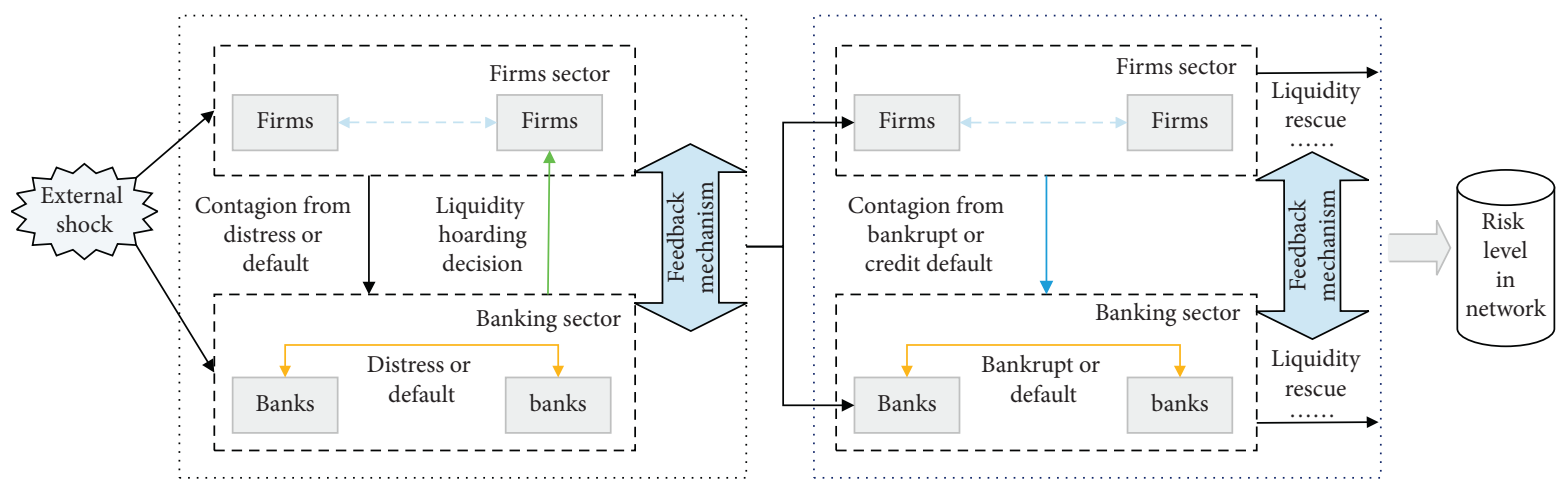

FIGURE 2: Diagram of systemic risk contagion mechanism in financial credit network within banks and firms.

of assets should meet the repayment of their loans to the banks. So, the relative changes of the shocked firms' equity and the survival ones within the network can be presented as $\left(\left(E_{f}(1)\right) /\left(E_{f}(0)\right)\right)=$ $1-m,\left(\left(E_{f}(2)\right) /\left(E_{f}(1)\right)\right)=1,\left(\left(E_{f}(3)\right) /\left(E_{f}(2)\right)\right)$ $=1,\left(\left(E_{f}(4)\right) /\left(E_{f}(3)\right)\right)=1 \ldots$ and $\left(\left(E_{f}(1)\right) /\right.$ $\left.\left.\left(E_{f}(0)\right)\right)=1,\left(\left(E_{f}(2)\right) / \quad E_{f}(1)\right)\right)=1,\left(\left(E_{f}(3)\right) /\right.$ $\left.\left.\left(E_{f}(2)\right)\right)=1,\left(\left(E_{f}(4)\right) / \quad E_{f}(3)\right)\right)=1 \ldots$, respectively, where $E_{f}(t) \leq 0, t \longrightarrow \infty$. Theoretically, systemic risk contagion could last until all banks go bankrupt, and $E_{i}(t) \leq 0$ will be the exact bankrupt benchmark for each agent.

As a matter of fact, except for credit risk and liquidity risk mentioned above, there are still lots of channels or factors resulting in risk spreading in financial networks. Specifically, the synchronization of these possible factors should accelerate or strengthen the risk contagion, which means that the impact of the outbreak of financial systemic risk in reality is likely to be worse than the analysis in this paper with certain constraints.

\section{Model of Systemic Risk Contagion in Financial Network}

The above reconstructed resulting bipartite network $G=$ $(B, F)$ consists of two sets of nodes: banks $B$ and firms $F$. In network, the links connect banks not only with other banks (interbank liabilities), but also with the firms (liabilities of firms or credit from the banks). The weighted links between each agent in all can be defined as liability matrix $L_{\left(N_{b}+N_{f}\right) *\left(N_{b}+N_{f}\right)}$, where each entry $L_{i j}$ indicates the liability that node $i$ has to node $j$, excluding the null entries between firms and the entries from firms to banks. Therefore, the reconstructed multilayer financial network can be partitioned into the following two types: interbank network and bank-firm network.

Let $A_{j i, \gamma}=\left\{a_{j i, \gamma}\right\}_{N * N(M)}$ be the adjacency matrix of the financial network; the credit relationship between each agent can be represented by these entries, where $a_{j i, \gamma}$ indicates the credit level of node $i$ to node $j$ in layer $\gamma$ and $\gamma$ indicates the network layer with different value. Specifically, it is assumed that there should be no circle credit relationship within each node's own, which means that $a_{j i, \gamma}=0$ is a default setting.

For simplicity, in asset side of a bank $i$ 's balance sheet, the asset $V_{i}$ is subdivided into the following three parts: interbank assets $V^{\mathrm{BI}}=\sum_{b=1}^{N} a_{b i}$, bank-firm assets $V^{\mathrm{FI}}=\sum_{f=1}^{M} a_{f i}$, and other assets $V^{\mathrm{OI}}$, while in liability side of the bank $i$ 's balance sheet it is also divided into three parts: interbank liabilities $L^{\mathrm{BI}}$, other liabilities $L^{\mathrm{OI}}$, and equity $E^{i}$, as is shown in Table 1. For interbank asset in each bank's balance sheet, there is a corresponding liability in another bank's balance sheet; that is, $L_{i j}=a_{j i}$, thus, interbank liabilities is $L^{\mathrm{BI}}=\sum_{b=1}^{N} a_{i b}$ and the rest liabilities can be calculated as $L^{\mathrm{OI}}(t)=V_{i}(t-1)-L^{\mathrm{BI}}-E_{i}(t-1)$. Overall, equity $E_{i}$ is used as a buffer of loss, and the relationship $V^{\mathrm{BI}}+$ $V^{\mathrm{FI}}+V^{\mathrm{OI}}=L^{\mathrm{BI}}+L^{\mathrm{OI}}+E_{i}$ is constant in common sense. Similarly, the simplified firm balance sheet can also be defined as that in Table 2.

4.1. General DebtRank Model. In order to measure the systemic risk and its dynamics of contagious process in financial network system, the DebtRank model, originally proposed by Battiston et al. [14] and Bardoscia et al. [48], is applied to be a special tool for measurement in this article. The original DebtRank model, transformed from PageRank algorithm [56], can be used to describe the dynamic process of stress propagation within interbank market successfully in several literatures. Briefly speaking, the DebtRank model could be adopted to quantify the extent of the financial distress that a particular node should face under the external shocks and the corresponding risk contagion within different channels. Therefore, a transition matrix called interbank market's vulnerability matrix $V \in B \times B$ can be created in the model, in which $B$ is the set of banks, and the vulnerability matrix can be defined as $V_{i j}=\left(A_{i j} / e_{i}\right)$, where $\forall i, j \in B$ and $V_{i j} \in[0, \infty)$. The entry $A_{i j}$ represents the unsecured exposure of creditor bank $i$ to debtor bank $j$, while $e_{i}>0$ denotes the capital buffer of bank $i$. Thus, when $V_{i j} \geq 1$, bank $j$ leads bank $i$ to default as well and the intermediate value of $V_{i j} \in(0,1]$ leads bank $i$ into distress but not into default.

In the general DebtRank model, two indicators are defined to measure the risk status of each node at each time step. One indicator is $H_{i}(t) \in[0,1]$, which represents the 
TABle 1: Simplified balance sheet of a bank.

\begin{tabular}{lc}
\hline Assets & Liabilities \\
\hline Interbank assets $V^{\mathrm{BI}}$ & Interbank liabilities $L^{\mathrm{BI}}$ \\
Bank-firm assets $V^{\mathrm{FI}}$ & Other liabilities $L^{\mathrm{OI}}$ \\
Other assets $V^{\mathrm{OI}}$ & Equity $E_{i}$ \\
\hline
\end{tabular}

TABle 2: Simplified balance sheet of a firm.

\begin{tabular}{lc}
\hline Assets & Liabilities \\
\hline Liquid assets $V^{F 1}$ & Bank-firm liabilities $L^{\mathrm{BF}}$ \\
\hline Nonliquid assets $V^{F 2}$ & Other liabilities $L^{\mathrm{OF}}$ \\
& Equity $E_{f}$ \\
\hline
\end{tabular}

vulnerability of node $i$, and the other one is $C_{i}(t)=\{U, D, I\}$, a discrete variable, representing the status of each shocked node $i$. By the way, the entries in the set of $C_{i}(t)$ represent the status of "Undistressed," "Distressed," and "Inactive," respectively. The specific modal indicators in the general DebtRank model can be seen as follows:

$$
\begin{aligned}
& H_{i}(t)=\min \left\{1, H_{i}(t-1)+\sum_{C_{j}(t-1)=D} W_{j i} H_{j}(t-1)\right\}, \\
& C_{i}(t)= \begin{cases}D, & H_{i}(t)>0 ; C_{i}(t-1) \neq I, \\
I, & C_{i}(t-1)=D, \\
C_{i}(t-1), & \text { otherwise. }\end{cases}
\end{aligned}
$$

The above DebtRank model always converges for $H_{i}(t)$ within the value by $H_{i}(t)=1$, due to the operator min, and shows nondecreasing monotonically, as a result of the nonnegative value in vulnerability matrix $V_{i j}=A_{i j} / e_{i}$.

Consequently, for a sufficiently large number of iteration steps $T<\infty$, the system converges to a stable status. The resulting DebtRank index DR is simply the additional stress that the interbank market suffers apart from the initial exogenous shock $b(0)$ that can be defined as follows:

$$
\operatorname{DR}(b(0))=\sum_{i \in B}\left(b_{i}(t)-b_{i}(0)\right) \varphi_{i},
$$

where $\varphi_{i}$ represents the economic importance of agent $i$, which can be simplified and designed to be the share of liabilities that agent $i$ has in the financial system. In this formula, $\mathrm{DR}(b(0))$ is conditional on the initial shock $b(0)$.

\subsection{Risk Measurement Model Based on General DebtRank} Model. The basic assumption of the general DebtRank model is that the loss or distress should be linearly transmitted from the debtor to the creditor and the devaluation of the debtor's equity leads to the devaluation of the creditor's assets on the same scale. Based on this, systemic risk contagion may result in potential loss of creditor assets, and the change of creditor's asset is related to that of debtor's equity.
Therefore, in this paper, changes of each bank's asset within interbank network and bank-firm market are described in the following formulas, respectively. Specifically, the credit amount of banks' drawing from the firms is considered to be the changes of assets in bank-firm market.

$$
\begin{aligned}
& a_{b i}(t+1)= \begin{cases}a_{b i, \gamma}(t) \frac{E_{b}(t)}{E_{b}(t-1)}, & E_{b}(t-1)>0, \\
a_{b i}(t)=0, & E_{b}(t-1) \leq 0,\end{cases} \\
& a_{f i}(t+1)= \begin{cases}a_{f i}(t) \frac{E_{f}(t)}{E_{f}(t-1)}, & E_{i}(t-1) \geq \varphi_{3} V_{i}(0), \\
a_{f i}(t), & E_{i}(t-1)<\varphi_{3} V_{i}(0) .\end{cases}
\end{aligned}
$$

Different from the original DebtRank model, where only the credit risk was considered, both liquidity risk and credit risk are taken into account in our optimized model, and the loss caused by the liquidity risk can be calculated as

$$
S_{i}=\frac{1-q}{q}\left\{m\left[V^{\mathrm{OI}}(0)+a_{f i}(0)\right]+\sum_{E_{b}(t-1) \leq 0} a_{b i}(t)\right\} .
$$

Therefore, based on the risk contagion process through the balance sheet in both asset side and liability side, the dynamic changes of equity in financial network can be microscopically drawn as

$$
\begin{aligned}
& E_{i}(t)=\sum_{b=1}^{N} a_{b i}(t)+\sum_{f=1}^{M} a_{f i}(t)+V_{i}^{\mathrm{OI}}(t)-L_{i}^{\mathrm{BI}}(t)-L_{i}^{\mathrm{OI}}(t) \\
& -S_{i},
\end{aligned}
$$

where $\quad V_{i}^{\mathrm{OI}}(t)=V_{i}^{\mathrm{OI}}(1)=(1-m) V_{i}^{\mathrm{OI}}(0), \quad V_{i}^{\mathrm{OI}}(t)=\varphi_{1}$ $V_{i}(0), L_{i}^{\mathrm{BI}}(t)=L_{i}^{\mathrm{BI}}(0)$, and $L_{i}^{\mathrm{OI}}(t)=L_{i}^{\mathrm{OI}}(0)$. The last two terms show the assumption that the debt is unchanged according to the face value.

According to the above analysis, the ration of risk exposure to equity is defined as the risk leverage matrix [48]. Concerning the deterioration of liquidity risk, the risk exposure should be magnified by $(1 / q)$ times potentially, which is mostly significant in short-term loans with high liquidity. According to formulas (3) and (4), the recursion process of the risk contagion can be drawn as in the following formula, on the condition that the risk exposure should not change in the first step; that is, $a_{j i, \gamma}(1)=a_{j i, \gamma}(0)$ :

$$
W_{j i, \gamma}(t)= \begin{cases}\frac{(1 / q) a_{j i, \gamma}(0)}{E_{i}(0)}, & E_{j}(t-1)>0 \\ 0, & E_{j}(t-1) \leq 0\end{cases}
$$

Thus, the maximum eigenvalue $\left|\lambda_{\max }\right|$ of the interbank leverage matrix can be calculated to characterize whether the risk of the external shock could be augmented in the risk 
contagion and leads to individual default. Additionally, concerning the reconstructed two-layer financial network, the risk status of each layer in the risk contagion can be measured by $H_{i, 1}(t)$ and $H_{i, 2}(t)$, respectively, where $H_{i, 1}(t)$ represents the banks' risk level in interbank lending layer and $H_{i, 2}(t)$ represents the banks' risk level in bank-firm lending layer.

$$
\begin{aligned}
& H_{i, 1}(t+1)=\min \left\{1, H_{i, 1}(t)+\sum_{b=1}^{N} W_{b i}\left[H_{b}(t)-H_{b}(t-1)\right]\right\}, \\
& H_{i, 2}(t+1)=\min \left\{1, H_{i, 2}(t)+\sum_{f=1}^{M} W_{f i}\left[H_{f}(t)-H_{f}(t-1)\right]\right\},
\end{aligned}
$$

where $H_{i, \gamma}(0)=0, H_{i, \gamma}(1)= \begin{cases}m, & \text { under initial shock, } \\ 0, & \text { otherwise }\end{cases}$ and $H_{f}(t)=\left\{\begin{array}{ll}0, & E_{f}(t)>0 \\ 1, & E_{f}(t) \leq 0\end{array}\right.$.

In original DebtRank algorithm, the node propagates the shock only once after receiving the shock. However, in this article, shocks could propagate until the agents default. Correspondingly, we optimize the DebtRank model so as to fit the new designed mechanism; therefore, the indicator $C_{i}(t)$ of the risk measurement can be adjusted into the one in the following formula:

$$
C_{i}(t)= \begin{cases}U, & H_{i}(t)=0, \\ D, & H_{i}(t) \in(0,1) \cap C_{i}(t-1)=\{U, D\}, \\ I, & H_{i}(t)=1 \cap C_{i}(t-1)=\{U, D\} .\end{cases}
$$

It is assumed that there be $X$ firms and $Y$ banks in initial distress state in this article. After a finite time step $T$, all banks in the multilayer financial network are in status $U$ or status $I$, and eventually the dynamics could tend to be stable in a certain scale.

\section{Simulation on Systemic Risk Contagion in Financial Network}

5.1. Simulation Parameters. Based on the above theoretical analysis, a series of computational simulations on systemic risk contagion and its impact on the stability of the financial network are conducted. Although various simulations with different settings will run, we confine some baseline set of the following parameters: the number of firms and banks should be set as $N_{f}=1000$ and $N_{b}=50$, respectively. The bank size distribution is assumed to be followed by a truncated Pareto distribution with shape parameter $\alpha=1.5$, and the boundaries of the nodes' links are set as $L=5$ and $H=200$. According to the empirical results in existing literatures, let the average number of links be $\lambda_{b}=100$ and $\lambda_{f}=10$ for banks and firms, respectively. Meanwhile, we make the assumption that each agent should possess at least one connection to the other ones and that each bank should be involved in the interbank credit market. Meanwhile, the parameter $\theta$ (initially set up as $28 \%$ ) of the amount of external assets will change systematically in the following experiment so as to explore how the different scenarios influence the vulnerability of the financial system. Additionally, the parameters of link-creating in interbank credit market should be set as $d=0.5, \alpha_{1}=0.25$, and $\alpha_{2}=1$ that can be employed to generate the disassortative features found in the actual market. Other than the above setting, we presume that the initial proportion of equity of total assets of the bank should be $\varphi_{2}=12 \%$ and the ratio of the credit drawn from the firm by the banks should be $\varphi_{3}=8 \%$.

Besides the above parameters, eight types of scenarios about the financial correlation condition within banking and firm sectors are assumed and conducted in simulation analysis, so that how the difference in risk contagion among each scenario can be compared and explored. Initially, all banks and firms are considered to be in the status of "Undistress." Concerning the eight types of scenarios, except from the network structure and the behavior of the agents, market liquidity and shock ratio are also the specific factors to be taken into account in the simulation. Therefore, these eight types of scenarios are divided into three categories in this article that have different value definition for each focused factor. The first category consists of four scenarios (Scenario 1-Scenario 4), which are conducted in the simulation to compare how the nodes' different initial distress states influence the risk contagion. The second category consists of two scenarios (Scenario 5 and Scenario 6), which are conducted in the simulation to compare how the different external shock ratios on assets influence the risk contagion process. The third category consists of two scenarios (Scenario 7 and Scenario 8), which are conducted in the simulation to compare how the different liquidity flow rates influence the risk contagion process. By the way, all the value setup of the related parameters is shown in Table 3.

Overall, in the whole eight scenarios, ten or more time steps are allowed in the simulation, so that we can observe the changeable state of banks' equity $E_{i}$ and risk measure indicators $H_{i}(t)$ and $C_{i}(t)$ until the time steps stop or the financial network system comes to a relative stable state. Therefore, the evolvement of systemic risk contagion process influenced by the factors of network structure, the nodes' initial risk status, the external shock ratio, and the asset flow rate in the network is comprehensively analyzed in the simulation.

5.2. Simulation Results. Based on the above assumption and definition, the following figures derived from the simulation experiment can absolutely prove the above theoretical viewpoints and give some additional meaningful information that all banks in the multilayered network would be affected in different scales in risk contagion process. Therefore, the simulation analysis is on how the systemic risk contagion is comprehensively conducted from the factors of the network structure, initial distress status of 
TABLE 3: Parameters in eight types of scenarios for simulation analysis.

\begin{tabular}{|c|c|c|}
\hline Scenarios & Descriptions & Value \\
\hline 4 & $\begin{array}{l}\text { Four scenarios are used to compare how the nodes' different initial distress influences the } \\
\text { risk contagion }\end{array}$ & $\begin{array}{c}m=0.01 \%, q=95 \%, X=1, \text { and } \\
Y=0 \\
m=0.01 \%, q=95 \%, X=0, \text { and } \\
Y=1 \\
m=0.01 \%, q=95 \%, X=1, \text { and } \\
Y=10 \\
m=0.01 \%, q=95 \%, X=10, \text { and } \\
Y=1\end{array}$ \\
\hline 6 & $\begin{array}{c}\text { Two scenarios are used to compare how the different external shock rates influence risk } \\
\text { contagion }\end{array}$ & $\begin{array}{c}m=0.1 \%, q=95 \%, X=5, \text { and } \\
Y=5 \\
m=10 \%, q=95 \%, X=5, \text { and } \\
Y=5\end{array}$ \\
\hline 8 & $\begin{array}{l}\text { Two scenarios are used to compare how the different assets flow rates influence risk } \\
\text { contagion }\end{array}$ & $\begin{array}{c}m=0.01 \%, q=95 \%, X=5 \text {, and } \\
Y=5 \\
m=0.01 \%, q=50 \%, X=5 \text {, and } \\
Y=5\end{array}$ \\
\hline
\end{tabular}

$m$ and $q$ represent the proportion of shocked agents and the liquidity flow rate, while $X$ and $Y$ represent the number of shocked banks and firms.

agents, the external shock ratio, the liquidity rate, and the layers of the network, by which the risk contagion process can be compared and analyzed.

\subsubsection{Impact on Risk Contagion from Network Structure.} How the linkage between each agent directly impacting the systemic contagious process is extremely important to both the speed of contagion and the extent of agent's failure. Therefore, in order to measure how the network structure (there are many indicators that can be applied to reflect the network structure, such as node density, degree distribution, diameter, and clustering coefficient; in this paper, two indicators of the average degree and the power law exponent of degree distribution are used) influences the risk contagion process, the related variables in simulation experiment could be assigned specific value. Specifically, the external shock ratio and the liquidity rate are defined as $0.01 \%$ and $95 \%$, respectively. Meanwhile, the average degree of interbank layer network and bank-firm layer network is defined as $\operatorname{Avd}_{\text {Interbank }}=5.8$ and $\mathrm{Avd}_{\text {bank-firm }}=4.5$, and the power law exponent of the degree distribution is defined as $\gamma=2.6$ in Figure 3(a). On the contrary, the average degree of interbank layer network and bank-firm layer network is defined as $\operatorname{Avd}_{\text {Interbank }}=8.9$ and Avd $\mathrm{d}_{\text {bank-firm }}=14.9$, and the power law exponent of the degree distribution is defined as $\gamma=2.9$ in Figure 3(b). On this assumption and definition, Figure 3 shows the losses of banks' equity over the time influenced by the different network structure of interbank credit network and bank-firm credit network, when five banks and five firms in the system are shocked to be in the status of "distress."

From Figures 3(a) and 3(b), it can be seen that almost all of the banks in reconstructed financial multiplex network go bankrupt within the fourth and tenth time step, which indicates that the speed of contagion is very high and the influential scope is relatively wide in both types of network structure. In Figure 3(b), the banks' equity drops suddenly from the start of the simulation that is different and a little bit slow in Figure 3(a). Comparing the banks' relative loss in Figure 3(b) with that in Figure 3(a), we can see that, in the two scenarios, as the average degree of the network increases, the speed and strength of risk contagion are significant. Therefore, for the more linkages within bank-firm credit network, distress or default from the bank-firm financial network could cause relatively more severe risk to the entire system, especially the postderived risk combined with the interbank market, which is extreme disaster and may be more intensive if the assumed credit relation is decomposed by actual complex financial correlation.

\subsubsection{Impact on Risk Contagion from Nodes' Initial Distress.} In financial network, the initial status of the agents should lead the whole financial system to different endings no matter what kind of intervention is and how it will be carried out. Consequently, let the average degree of interbank network and the bank-firm network be $\operatorname{Avd}_{\text {Interbank }}=5.8$ and $\operatorname{Avd}_{\text {bank-firm }}$ $=14.9$, respectively. Meanwhile, four types of scenarios with different quantity and category of shocked agents will be selected to explore how the nodes' initial status influences the risk contagion, whose corresponding simulation results can be seen in Figure 4. As shown in Figure 4, most banks in the reconstructed two-layer financial network almost have significant loss between the fourth and the fifth time steps, which shows that the speed of risk contagion is absolutely high and the influence is extremely wide no matter which scenario is tested.

Figures 4(a) and 4(b) show the relative loss of the banks with external shocks randomly on one bank and one firm, respectively, while it can be seen that the losses of banks' equity come out in a little bit faster speed in Figure 4(b) with almost no obvious difference. Meanwhile, the significant different simulation results can be obtained between Figures $4(\mathrm{~d})$ and $4(\mathrm{c})$, where the scenario with five banks and one firm being shocked simultaneously is assumed in Figure 4(c), and the scenario with one bank and five firms 


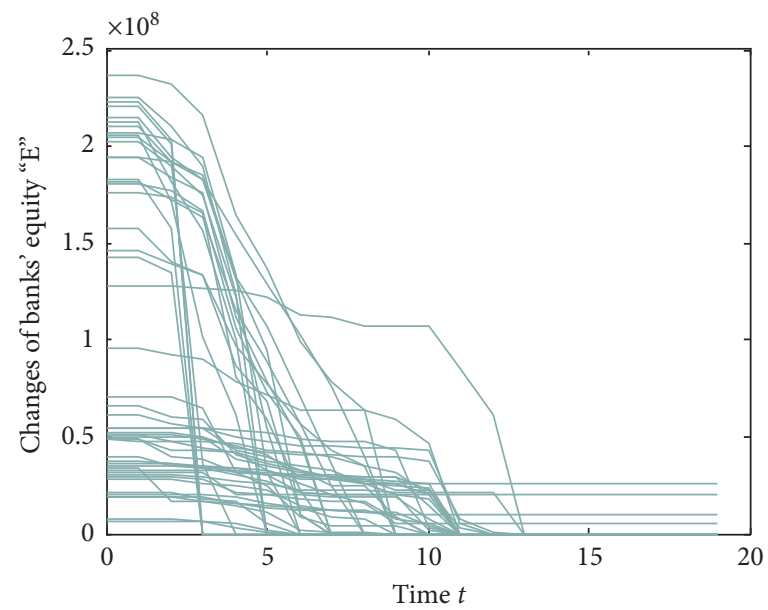

(a)

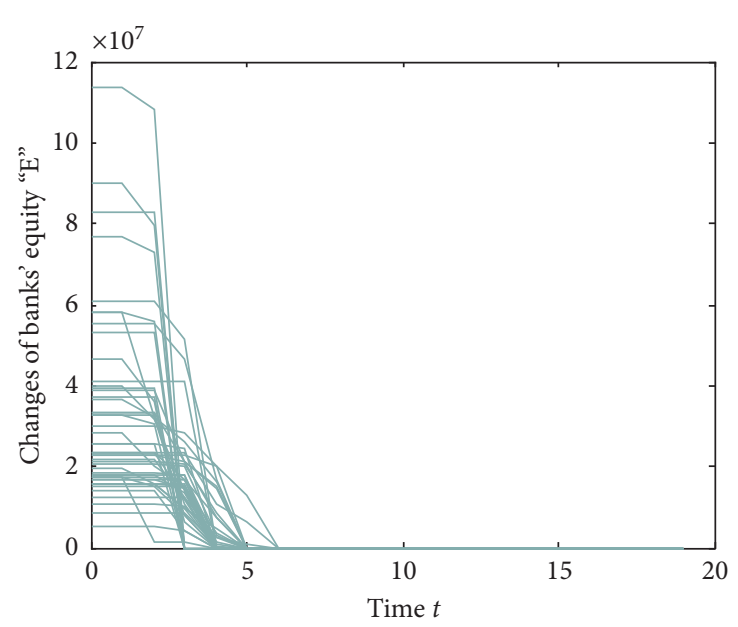

(b)

FIGURE 3: Losses of banks' equity over time influenced by different network structures.

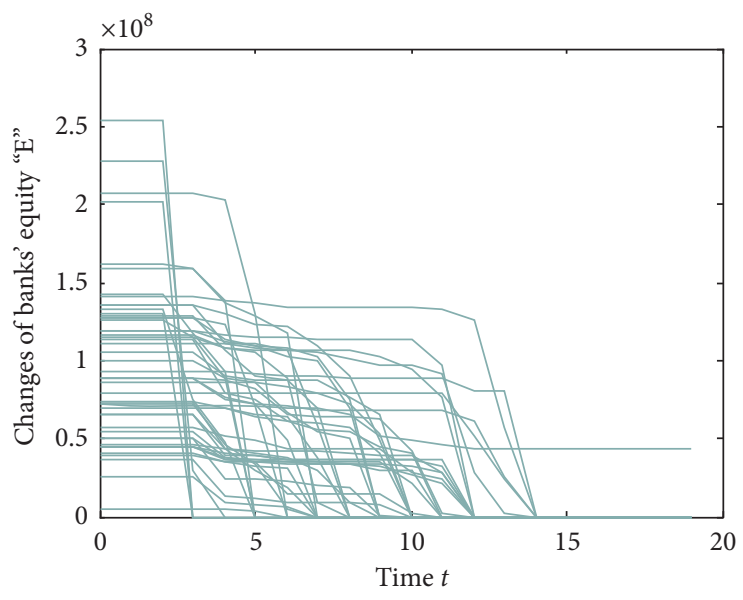

(a)

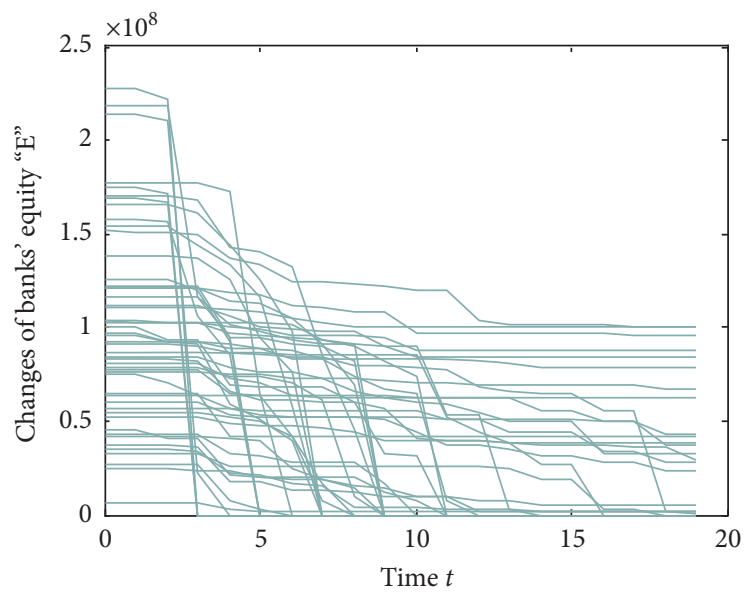

(c)

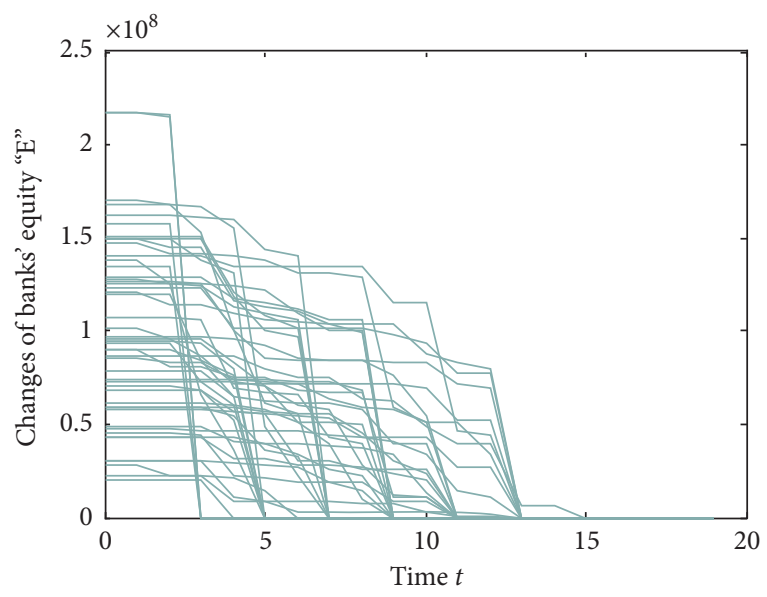

(b)

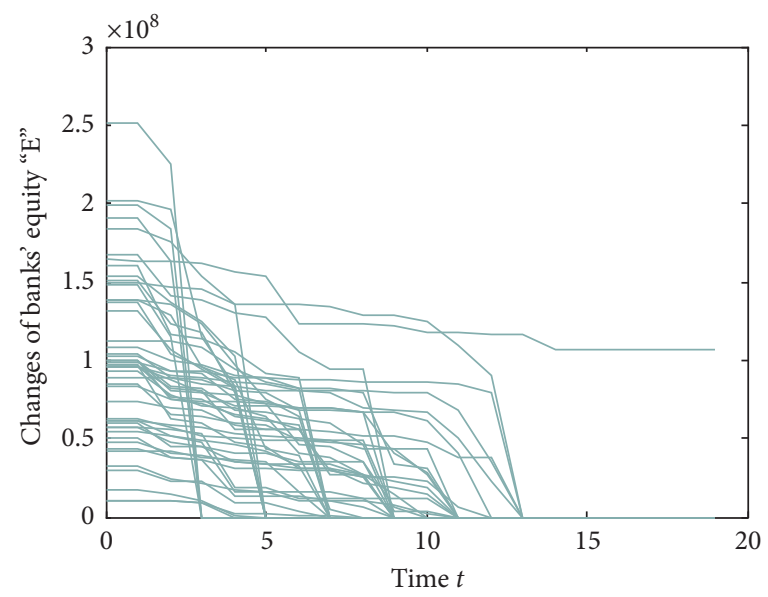

(d)

FIgURE 4: Losses of banks' equity over time influenced by nodes' different initial distress status. 
being shocked simultaneously is shown in Figure 4(d). In Figure 4(c), the decrease of the banks' equity is slower than that in Figure 4(d), and part of the banks survived as the time goes at last. Besides, we can find that the speed of systemic risk contagion in Figure 4(d) is nearly the fastest among all the four scenarios, which implies that some firms in the financial system also play crucial roles in risk contagion. Therefore, from the simulation on all four types of scenarios about the systemic risk contagion, the conclusion is that the risks resulting from the failed firms should place more negative effect on the financial systems than that only happening in interbank market. According to that, risks from the real economy in the measurement of systemic risk contagion in financial system should be also taken into account for the complex financial correlation in the economy especially the potential feedback mechanism in the contagious process, which may cause unimaginable disaster.

\subsubsection{Impact on the Systemic Risk Contagion from External} Shock Ratio. A sudden incidence on economy may cause a huge loss even if the whole system collapses. Thus, how the accidental events affect the systemic risk contagion should be analyzed theoretically for the practical regulation. Based on the fifth and the sixth scenarios, average degree of the interbank network and the bank-firm network is also defined as $\mathrm{Avd}_{\text {Interbank }}=5.7$ and $\mathrm{Avd}_{\text {bank-firm }}=14.9$, respectively, and the other parameters follow the default definition. Figure 5 presents the changes of proportion of the banks' status during the systemic risk contagion process under different external shock ratios, which are defined as $0.1 \%$ in Figure $5(\mathrm{a})$ and $10 \%$ in Figure 5(b), respectively.

From Figure 5, we can see that almost most of the banks turn to the state of " $I$," which means that these banks go bankrupt, but the evolving process shows difference between the two scenarios. In both Figures 5(a) and 5(b), there will be no banks being totally healthy within the first three time steps, and meanwhile almost all of the banks come to the state of " $D$," no matter what the external shock ratio is. As time goes, the proportion of the banks with the state of " $I$ " goes up quickly and the proportion of the banks with the state of " $D$ " comes down accordingly. However, within the twenty time steps, the proportion of banks with the state of " $D$ " is almost zero in Figure 5(b), while that proportion in Figure 5(a) comes to $30 \%$. Besides, the changes of proportion of the banks' state are rapid in Figure 5(b), which conveys the implication that relatively high external shock ratio results in more harmful risk contagion on the condition of the simulation. Therefore, some suggestion on financial risk management for the regulation authorities can be drawn that proper intervention should be implemented in the specific period of systemic risk contagion process. However, the intervention from the outside of the financial system should not be simply considered as rescuing some banks or firms unconditionally.

5.2.4. Impact on Systemic Risk Contagion from Liquidity Rate. For liquidity rate could be an influencing factor in credit network-based risk contagion, how it works should be evaluated in the simulation more in detail. According to the seventh and the eighth scenarios presumed above and all other parameters being defined as the default setup, Figure 6 shows the losses of the proportion of banks' equity over time under different liquidity rates.

In Figures 6(a) and 6(b), most of the banks go bankrupt within the fourth and fifteenth time step, and the changes of banks' equity follow almost similar track, while the liquidity ratios are defined as $50 \%$ and $95 \%$, respectively, for the comparative simulation analysis. However, there is also obvious difference between the two evolvement processes. Compared with the evolving tract in Figure 6(a), the time span of the banks' bankruptcy lasts a little bit longer, and the time span for banks' failure and the banks' equity decreases to a relative state which are presented in more concentration in Figure 6(b). Specifically, the survival of banks' equity in Figure 6(b) is also larger than that in Figure 6(a). From the simulation results, we can find that liquidity rate indeed places impact on the speed of risk contagion and the degree of asset loss in that process. Thus, some advice may be provided for risk management that liquidity control should be a paramount means to prevent or manipulate risk contagion, implemented dynamically not only in the risk contagious process, but also in the specific polices or regulations for firm sectors and financial sectors in various industries.

\subsubsection{Impact on Risk Contagion from Network's Different} Layers. Based on the above definition about the parameter setting, this section aims to find out how the layers of the reconstructed financial network, both interbank network layer and bank-firm network layer, affect the systemic risk contagion process. Just like the above sectors, let the average degree of the interbank network and the bank-firm network be $\operatorname{Avd}_{\text {Interbank }}=5.8$ and $\operatorname{Avd}_{\text {bank-firm }}=14.9$, respectively. Meanwhile, it is assumed that liquidity rate be defined as 95\% and five banks and five firms be shocked by external shock. Further, we conduct the simulation analysis to measure the systemic risk by the variable $H$ within contagious process, which means the relative loss of the agents or the system along the time steps shown in Figure 7.

From Figure 7, we can see that track of $H$ values' changes over time in Figures 7(a) and 7(b) which is totally different. Figure 7 (a) shows the changes of value $H$ of the banks over time in interbank credit networks, while Figure 7(b) shows that value in bank-firm credit networks. Obviously, compared with the track of $H$ values' changes in interbank layer 


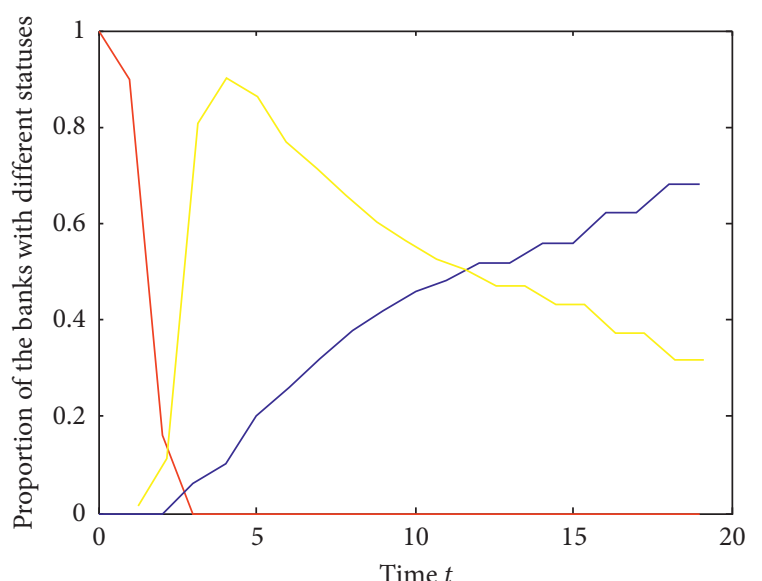

_ Proportion of the banks with $U$

- Proportion of the banks with $I$

- Proportion of the banks with $D$

(a)

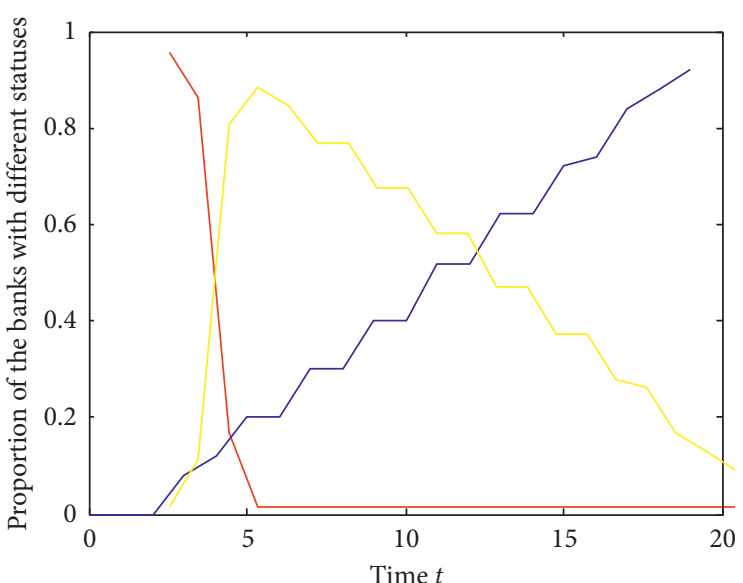

- Proportion of the banks with $U$

- Proportion of the banks with I

Proportion of the banks with $D$

(b)

FIGURE 5: Changes of proportion of banks' status over time under different external shock ratios.

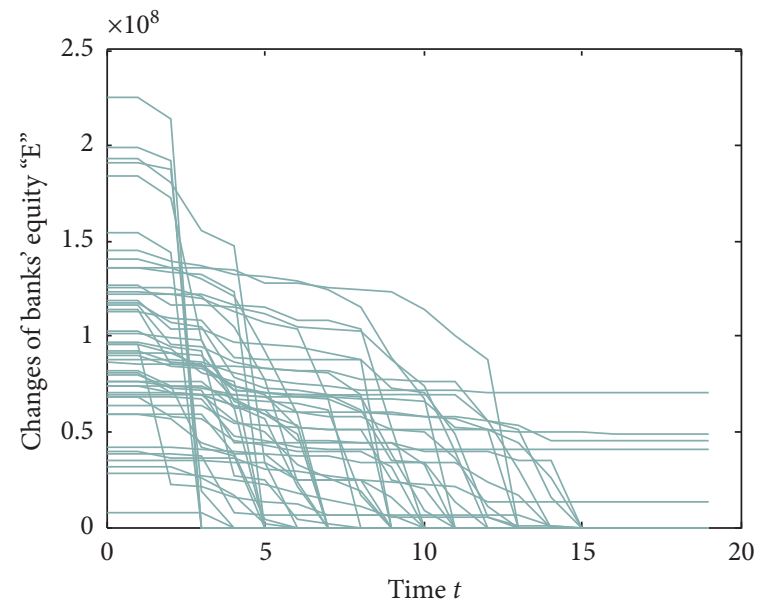

(a)

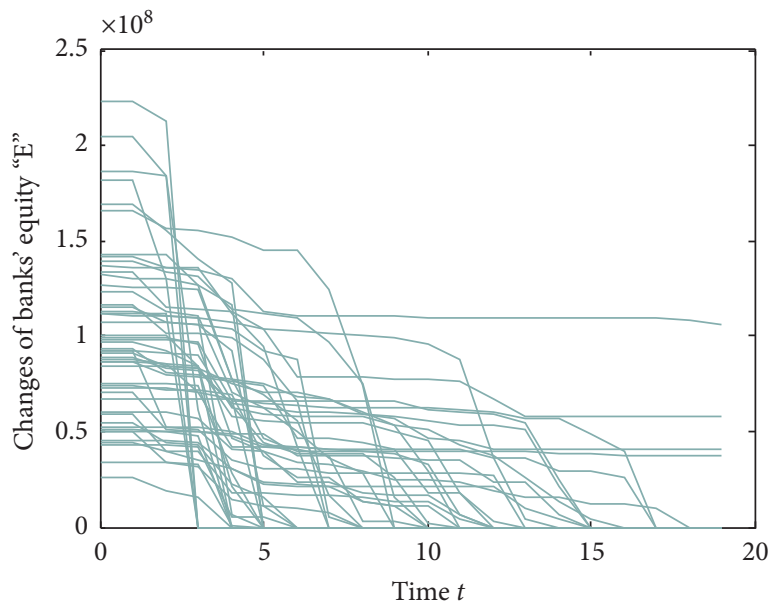

(b)

FIGURE 6: Changes of proportion of banks' equity over time under different liquidity rates.

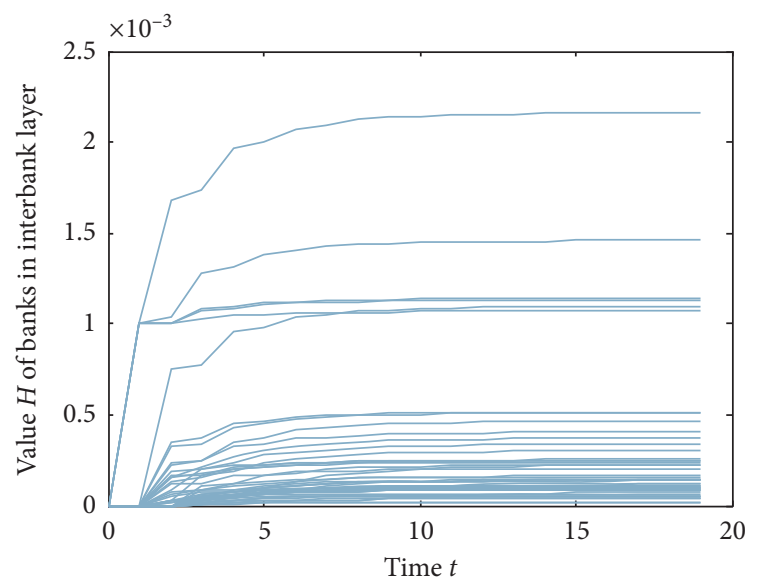

(a)

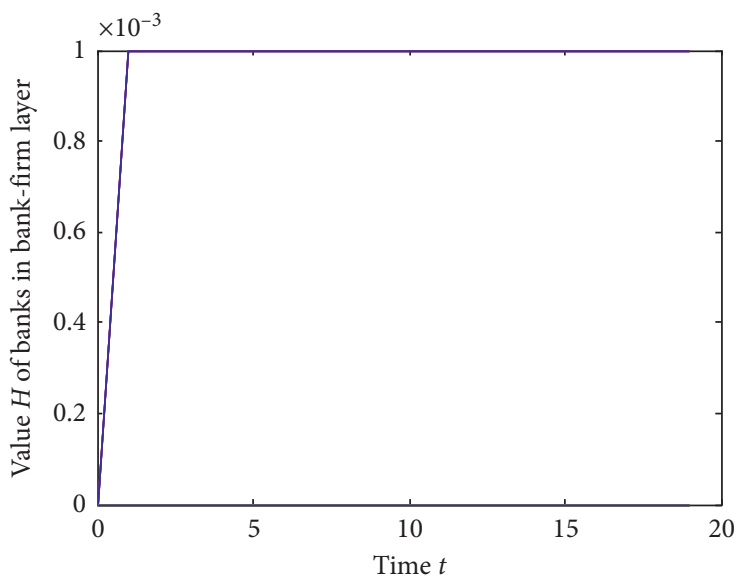

(b)

Figure 7: Changes of $H$ values over time in different network layers. 
of the reconstructed multiplex networks, the bank-firm layer is much more likely to cause banks' bankruptcy eventually. In Figure 7(a), only a few parts of banks will absolutely go bankrupt, and most of the banks just come to be the stable state of distressed or infectious ones as the time steps go. However, in Figure 7(b), when it almost comes to the third time step, all of the banks turn to be bankrupt suddenly. To some extent, the simulation results can also propose an obvious viewpoint that bank-firm credit market plays a significant role in the process of risk contagion, so that the regulatory authorities should take into account the complex correlations between the industrial sectors and the financial sectors systematically when establishing and implementing related polices, and they cannot ignore the impact on the financial system from real economy at all.

\section{Conclusion}

The theory of multilayer network provides a comprehensive visualization and solution to explore complex financial markets. In this article, a two-layer financial credit network is reconstructed between banking and firm sectors on the structure of each agent's balance sheet generally, consisting of interbank lending layer and bank-firm lending layer. Based on the reconstructed financial network, systemic risk is considered as a status of loss or distress of the financial system including credit risk and liquidity risk in this article, and its contagion mechanism has been systemically analyzed. Thereafter, systemic risk contagion model is constructed on the DebtRank model, originally proposed by Battiston et al. [14] and Bardoscia et al. [48]; and the simulation analysis is conducted to investigate how the key factors influence risk contagion process due to external and internal shocks.

The main conclusions are drawn as follows: (1) in reconstructed financial network, network structure is an important factor influencing the risk contagious process, no matter how different the average degree of each layer network is. For the scale-free characteristic of the designed network, nearly all of the banks should be bankrupt over time in the simulation without any external intervention on the basic definition of the risk contagion circumstance, but the changes of banks' equity show different evolving process. Overall, the higher the average degree of the network is, the more influential and faster the risk contagion is. (2) In the two-layered financial networks, risks that originated from the failed firms in bank-firm layer should place more negative effect on the financial systems than that only happening in interbank market, especially the firm sectors with highly financial linkage with the financial departments. Meanwhile, how the external shock ratio placing impact on the risk contagion can also be obtained that the higher the initial shock ratio, the lower the peak proportion value of the distressed banks. (3) As a major cause of systemic risk, different liquidity rate in market could lead to discrepancy of the risk contagion speed and the degree of asset loss during the process, which implies that liquidity control should be a paramount and effective means to risk manipulating and the methods should be developed and implemented for the industries collaboratively. (4) In the same assumed market condition, track of $H$ values' changes over time presents obvious difference in interbank layer and bank-firm layer, respectively, where nearly all of the banks go bankrupt eventually in bank-firm layer and most of the banks are not in bad condition in interbank layer. Therefore, these simulation results give clear evidence that a series of diverse and associated policies for risk management should be established and implemented in the market.

However, the reconstructed financial credit network within banking and firm sectors in this article mainly focuses on the credit relationship between banks and from banks to firms, while the financial correlation between firms and from firms to banks is not considered comprehensively that would result in underestimating the systemic risk. Besides, there are more financial correlations within different types of agents, directly or indirectly, such as common exposure, derivatives holding, and payment transaction. What is more, concerning the systemic risk model and its simulation analysis, attention has been paid to how banks go in risk contagious process, while it is also important to care about the firms' status and the feedback mechanism between both sectors. Therefore, all these gaps should be fulfilled in future research.

\section{Data Availability}

All data used in this article are available from the corresponding author upon request.

\section{Conflicts of Interest}

The authors declare that they have no conflicts of interest.

\section{Acknowledgments}

This research was supported by the National Planning Office of Philosophy and Social Science (Grant no. 19BJY255), the National Natural Science Foundation of China (Grant nos. 71372181 and 71301078), Youth Foundation Project of Humanities and Social Sciences of Ministry of Education in China (Grant no. 17YJC790002), Key Projects of Social Science by Jiangsu Province (Grant no. 18EYA002), the Sponsorship of Jiangsu Overseas Visiting Scholar Program for University Prominent Young and Middle-aged Teachers and Presidents in 2018, and the Teaching Reform Project of Nanjing Normal University in 2019 (Grant no. 2019NSDJG025).

\section{Supplementary Materials}

The supplementary material includes the main part of the pseudocode for the simulation analysis on the financial contagion. All the pseudocode can be modified and 
conducted in the software platform of MATLAB 2014(a) or newer version. (Supplementary Materials)

\section{References}

[1] M. F. Hellwig, "Systemic risk in the financial sector: an analysis of the subprime-mortgage financial crisis," De Economist, vol. 157, no. 2, pp. 129-207, 2009.

[2] J. E. Stiglitz, "Risk and global economic architecture: why full financial integration may Be undesirable," American Economic Review, vol. 100, no. 2, pp. 388-392, 2010.

[3] D. Acemoglu, A. Ozdaglar, and A. Tahbaz-Salehi, "Systemic risk and stability in financial networks," American Economic Review, vol. 105, no. 2, pp. 564-608, 2015.

[4] J. Yellen, Interconnectedness and Systemic Risk: Lessons from the Financial Crisis and Policy Implications, Speech at the American Economic Association/American Finance Association, San Diego, CA, USA, 2014.

[5] P. Hartmann and O. De Bandt, Systemic Risk: A Survey, Social Science Electronic Publishing, Rochester, NY, USA, 2000.

[6] BIS, Addressing Financial System Procyclicality: A Possible Framework, BIS, Basel, Switzerland, 2010.

[7] C. Upper and A. Worms, "Estimating bilateral exposures in the German interbank market: is there a danger of contagion?" European Economic Review, vol. 48, no. 4, pp. 827-849, 2004.

[8] D. O. Cajueiro, B. M. Tabak, and R. F. Andrade, "Fluctuations in interbank network dynamics," Physical Review E Statistical Nonlinear \& Soft Matter Physics, vol. 79, no. 2, Article ID 037101, 2009.

[9] P. Gai and S. Kapadia, "Contagion in financial networks," Proceedings of the Royal Society A: Mathematical, Physical and Engineering Sciences, vol. 466, no. 2120, pp. 2401-2423, 2010.

[10] D. Fricke and T. Lux, "Core-periphery structure in the overnight money market: evidence from the e-MID trading platform," Computational Economics, vol. 45, no. 3, pp. 359-395, 2015.

[11] G. Iori, G. De Masi, O. V. Precup, G. Gabbi, and G. Caldarelli, "A network analysis of the Italian overnight money market," Journal of Economic Dynamics and Control, vol. 32, no. 1, pp. 259-278, 2008.

[12] G. Iori, R. N. Mantegna, L. Marotta, S. Miccichè, J. Porter, and M. Tumminello, "Networked relationships in the e-MID interbank market: a trading model with memory," Journal of Economic Dynamics and Control, vol. 50, pp. 98-116, 2015.

[13] F. Allen and D. Gale, "Financial contagion," Journal of Political Economy, vol. 108, no. 1, pp. 1-33, 2000.

[14] S. Battiston, M. Puliga, R. Kaushik, P. Tasca, and G. Caldarelli, "DebtRank: too central to fail? financial networks, the FED and systemic risk," Scientific Reports, vol. 2, p. 541, 2012.

[15] R. Cifuentes, G. Ferrucci, and H. S. Shin, "Liquidity risk and contagion," Journal of the European Economic Association, vol. 3, no. 2-3, pp. 556-566, 2005.

[16] E. Nier, J. Yang, T. Yorulmazer, and A. Alentorn, "Network models and financial stability," Journal of Economic Dynamics and Control, vol. 31, no. 6, pp. 2033-2060, 2007.

[17] R. Greenwood, A. Landier, and D. Thesmar, "Vulnerable banks," Journal of Financial Economics, vol. 115, no. 3, pp. 471-485, 2015.

[18] S. Markose, S. Giansante, and A. R. Shaghaghi, "Too interconnected to fail" financial network of US CDS market: topological fragility and systemic risk," Journal of Economic Behavior \& Organization, vol. 83, no. 3, pp. 627-646, 2012.
[19] R. J. Caballero and A. Simsek, "Fire sales in a model of complexity," The Journal of Finance, vol. 68, no. 6, pp. 2549-2587, 2013.

[20] F. Caccioli, M. Shrestha, C. Moore, and J. D. Farmer, "Stability analysis of financial contagion due to overlapping portfolios," Journal of Banking \& Finance, vol. 46, pp. 233-245, 2014.

[21] B. S. Bernanke, "Central bank independence, transparency, and accountability," in Proceedings of the Speech at the Institute for Monetary and Economic Studies International Conference, vol. 25, Bank of Japan, Tokyo, Japan, May 2010.

[22] F. Alvarez and G. Barlevy, "Mandatory disclosure and financial contagion," National Bureau of Economic Research, Cambridge, MA, USA, No. w21328, 2015.

[23] A. G. Haldane and R. M. May, "Systemic risk in banking ecosystems," Nature, vol. 469, no. 7330, pp. 351-355, 2011.

[24] M. Billio, M. Getmansky, A. W. Lo, and L. Pelizzon, "Econometric measures of connectedness and systemic risk in the finance and insurance sectors," Journal of Financial Economics, vol. 104, no. 3, pp. 535-559, 2012.

[25] T. Roukny, H. Bersini, H. Pirotte et al., "Default cascades in complex networks: topology and systemic risk," Scientific Reports, vol. 3, Article ID 2759, 2013.

[26] S. Poledna, J. L. Molina-Borboa, S. Martínez-Jaramillo, M. van der Leij, and S. Thurner, "The multi-layer network nature of systemic risk and its implications for the costs of financial crises," Journal of Financial Stability, vol. 20, pp. 70-81, 2015.

[27] M. Montagna and C. Kok, "Multi-layered interbank model for assessing systemic risk," European Central Bank, Frankfurt, Germany, Working Paper Series, 2016.

[28] M. Bluhm and J. P. Krahnen, "Systemic risk in an interconnected banking system with endogenous asset markets," Journal of Financial Stability, vol. 13, no. 1, pp. 75-94, 2014.

[29] C. León, R. Berndsen, and L. Renneboog, "Financial stability and interacting networks of financial institutions and market infrastructures," European Banking Center, Lancaster, UK, European Banking Center Discussion Paper Series 2014-011, 2014.

[30] L. Bargigli, G. di Iasio, L. Infante, F. Lillo, and F. Pierobon, "The multiplex structure of interbank networks," Quantitative Finance, vol. 15, no. 4, pp. 673-691, 2015.

[31] G. Peralta and R. Crisóstomo, Financial Contagion with Collateralized Transactions: A Multiplex Network Approach, Social Science Electronic Publishing, Rochester, NY, USA, 2016.

[32] Y. Korniyenko, M. Patnam, R. M. D. Rio-Chanona, and M. A. Porter, "Evolution of the global financial network and contagion: a new approach," IMF Staff Papers, vol. 18, no. 113, 2018.

[33] S. Li, M. Liu, L. Wang, and K. Yang, "Bank multiplex networks and systemic risk," Physica A: Statistical Mechanics and Its Applications, vol. 533, Article ID 122039, 2019.

[34] V. Nicosia, G. Bianconi, V. Latora, and M. Barthelemy, "Growing multiplex networks," Physical Review Letters, vol. 111, no. 5, Article ID 058701, 2013.

[35] J. Y. Kim and K. I. Goh, "Coevolution and correlated multiplexity in multiplex networks," Physical Review Letters, vol. 111, no. 5, Article ID 058702, 2013.

[36] M. Szell and S. Thurner, "Measuring social dynamics in a massive multiplayer online game," Social Networks, vol. 32, no. 4, pp. 313-329, 2010.

[37] Y. Fujiwara, H. Aoyama, Y. Ikeda, H. Iyetomi, and W. Souma, "Structure and temporal change of the credit network between 
banks and large firms in Japan. Economics: the open-access," Open-Assessment E-Journal, vol. 3, no. 2009-7, pp. 1-18, 2009.

[38] G. De Masi and M. Gallegati, "Bank-firms topology in Italy," Empirical Economics, vol. 43, no. 2, pp. 851-866, 2012.

[39] H. Aoyama, "Systemic risk in Japanese credit network," in Econophysics of Agent-Based Models, pp. 219-228, Springer, Berlin, Germany, 2014.

[40] L. Marotta, S. Micciche, Y. Fujiwara et al., "Bank-firm credit network in Japan: an analysis of a bipartite network," PLoS One, vol. 10, no. 5, Article ID e0123079, 2015.

[41] G. De Masi, Y. Fujiwara, M. Gallegati, B. Greenwald, and J. E. Stiglitz, "An analysis of the Japanese credit network," Evolutionary and Institutional Economics Review, vol. 7, no. 2, pp. 209-232, 2011.

[42] R. Miranda and B. Tabak, "Contagion risk within firm-bank bivariate networks," Tech. rep., Central Bank of Brazil, Research Department, Brasilia, Brazil, 2013.

[43] T. Lux, "A model of the topology of the bank-firm credit network and its role as channel of contagion," Journal of Economic Dynamics and Control, vol. 66, pp. 36-53, 2016.

[44] T. Adrian and M. Brunnermeier, "Covar," Tech. Rep., National Bureau of Economic Research, Cambridge, MA, USA, 2011.

[45] V. Acharya, L. Pedersen, T. Philippon, and M. Richardson, "Measuring systemic risk," CEPR Discussion Papers, Tech. Rep., CEPR, London, England, 2012, http://ssrn.com/ abstract $=1573171$.

[46] C. T. Brownlees and R. Engle, "Volatility, correlation and tails for systemic risk measurement," New York University, New York, NY, USA, Work Paper, SSRN 1611229, 2012.

[47] P. Glasserman and H. P. Young, "How likely is contagion in financial networks?" Journal of Banking \& Finance, vol. 50, pp. 383-399, 2015.

[48] M. Bardoscia, S. Battiston, F. Caccioli, and G. Caldarelli, "DebtRank: a microscopic foundation for shock propagation," PLoS One, vol. 10, no. 6, Article ID e0134888, 2015.

[49] T. C. Silva, M. A. da Silva, and B. M. Tabak, "Systemic risk in financial systems: a feedback approach," Journal of Economic Behavior \& Organization, vol. 144, pp. 97-120, 2017.

[50] S. Poledna, A. Hinteregger, and S. Thurner, "Identifying systemically important companies in the entire liability network of a small open economy," 2018, http://arxiv.org/abs/ $1801.10487 \mathrm{v} 1$.

[51] M. Montagna and T. Lux, "Hubs and resilience: towards more realistic models of interbank markets," in Financial Integration and Financial Crisis: Some Recent Developments, I. Arribas and E. Tortosa-Ausina, Eds., FundaciónBBVA, Bilbao, Spain, 2015.

[52] J. F. Cocco, F. J. Gomes, and N. C. Martins, "Lending relationships in the interbank market," Journal of Financial Intermediation, vol. 18, no. 1, pp. 24-48, 2009.

[53] B. Craig and G. Von Peter, "Interbank tiering and money center banks," Journal of Financial Intermediation, vol. 23, no. 3, pp. 322-347, 2014.

[54] K.-I. Goh, B. Kahng, and D. Kim, "Universal behavior of load distribution in scale-free networks," Physical Review Letters, vol. 87, no. 27, Article ID 278701, 2001.

[55] P. Crosbie and J. Bohn, "Modeling default risk," KMV, New York, NY, USA, Working Paper, 2003.

[56] S. Brin and P. Lawrence, "The anatomy of a large-scale hypertextual web search engine," Computer Networks and ISDN Systems, vol. 30, pp. 107-117, 1998. 